\title{
Radiation hazards to the cardiologist
}

\author{
A report of a subcommittee of the British Cardiac Society
}

In 1988 a Working Party of the Cardiology Committee of the Royal College of Physicians and the Royal College of Radiologists issued a short report Radiation Protection as Applied to Cardiology. This report stressed the importance of adequate training in radiation protection and appropriate working practice. In the report the introduction of interventional procedures was identified as a cause of some concern. Interventional techniques such as angioplasty, balloon dilatation of valves, and catheter ablation are now commonly used. Recent reports of the exposure of cardiologists/radiologists to high levels of radiation during some of these procedures have prompted the British Cardiac Society to commission the present report.

The present report refers to the operator as "the cardiologist" but we recognise that radiologists too perform coronary angiography, cardiac catheterisation, coronary angioplasty, and other interventional procedures. Radiologists, unlike cardiologists, are frequently involved in $x$ ray based procedures other than those involving the heart and so are probably more aware of the cumulative occupational radiation exposure. Some studies have shown that interventional cardiologists may be receiving a higher dosage than their radiological counterparts, which suggests that there may be room for improvement in the radiation hygiene of cardiologists.

\section{Committee}

membership

A J Camm (chairman),

$\mathrm{J}$ Reid (Royal College of

Radiologists),

M Raphael (British

Cardiac Society),

$P$ Wilde (Royal College

of Radiologists),

R Boyle (British Cardiac

Society),

M Clarke (British Pacing

\& Electrophysiology

Group),

S Qureshi (British

Paediatric Cardiac

Association),

M Rothman (British

Cardiovascular

Interventional Society),

A Shaw (Institute of

Physical Sciences in

Medicine)

Correspondence to:

Professor A. John Camm

Droparsor A. John Camm,

Sciences, Medical Scho
St. George's Hospital,

Cranmer Terrace, London,

SW17 0RE
For this reason control of the prim beam is one of the two major ways of reducing irradiation of staff and patients and of improving image quality. The type of scatter produced depends on the energy of the pri- mary beam. Low energy (low $\mathrm{kVp}$ ) beams produce low energy scatter that tends to be absorbed within the patient and not to escape to irradiate the staff or to degrade the image. Thus oblique (thick) projections through the patient, which drive up the $\mathrm{kVp}$, increase patient and staff dose and reduce picture quality. Projections where the $x$ ray tube (under couch) is on the same side as the operator result in exposures that are 10 times higher than when the image intensifier is on the same side as the operator.

A serious side effect of increasing the $\mathrm{kVp}$ is that the iodine absorption of $x$ rays declines and hence the quality of visualisation by the contrast agent deteriorates. All cardiologists see this in their daily practice, where the radiographic quality of LAO cranial and RAO caudal views is much lower than PA or RAO projections in the same patient. Often, however, the choice of projection is not open to us because the requirement to remove overlap and foreshortening are of fundamental importance and may demand a thick projection.

\section{DOSE QUANTITIES}

The absorbed dose is a measure of the amount of energy imparted per unit mass by ionising radiation to a tissue or organ. The special unit for absorbed dose is the gray (Gy). One gray is equivalent to one joule per kilogram.

Different types of radiation cause various biological effects. The equivalent dose weights the absorbed dose for the harmfulness of each radiation type. For $x$ rays, the radiation weighting factor is unity so that the equivalent dose, measured in sieverts (Sv), equals the absorbed dose in grays.

The equivalent dose received by different tissues (or organs) is frequently non-uniform, particularly in diagnostic radiology, while the susceptibility to harm from a given radiation dose is also tissue dependent. The concept of effective dose is introduced so that risks associated with irradiation of various tissues can be added to determine the risk to the body as a whole. This is the most useful quantity for assessing and comparing overall risk. The effective dose is defined as the sum of the equivalent doses to all tissues, each weighted with the relative risk (mainly of cancer production) for the specific tissue. The tissue weighting factors, which have recently been revised (ICRP 1991), add up to unity so that the sum of risks to individual tissues receiving 
a given dose is the same as the risk from uniform whole body irradiation at that dose level. The effective dose is also measured in sieverts.

\section{DOSE LIMITS}

The system of protection recommended by the International Commission on Radiological Protection (ICRP) for all practices that involve radiation exposure to people is based on the principles that the practice must be justified, that all exposures should be as low as reasonably achievable (ALARA principle), and that individual exposures are subject to dose limits (table 1).

United Kingdom legislation laid out in the Ionising Radiations Regulations (1985), based on earlier ICRP recommendations (ICRP 1977) has similar equivalent dose limits for specific organs but stipulates higher effective dose limits for occupationally exposed individuals (table 2 ).

In view of the increased risk estimates in the more recent ICRP recommendations (ICRP 1991) additional guidance has been published, as an adjunct to the 1985 regulations (Health and Safety Commission 1991). This aims to restrict a worker's exposure to less than three tenths of $15 \mathrm{mSv}$ per year, averaged over any five consecutive years and details a course of action if this constraint is exceeded. The National Radiological Protection Board (NRPB) commenting on the ICRP recommendations also concludes that "once pregnancy is declared, the exposure of the pregnant woman should be further restricted so as to limit the effective dose at the fetus to $1 \mathrm{mSv}$ " (NRPB 1991).

Dose limits are set at a level above which risk is considered unacceptable. The latest risk estimate for a fatal cancer averaged for a population of working age is $4 \%$ per sievert (ICRP 1991), so that an annual effective dose of $15 \mathrm{mSv}$ would represent a cancer risk of 1 in 1667 per year. The dose limits for the lens of the eye and the skin are set to prevent deterministic radiation effects that occur above a threshold dose level.

\section{Dose monitoring}

The Ionising Radiations Regulations (IRR) 1985 require that any employee likely to exceed three tenths of any relevant dose limit must be designated as classified. Classified workers are subject to individual dose assessment and medical surveillance. Personal dose assessment of non-classified workers may be carried out to demonstrate that doses are restricted to below the classification level.

Table 1 ICRP radiation dose limits for occupationally exposed individuals

\begin{tabular}{ll}
\hline Dose quantity & Annual dose limit \\
\hline Effective dose & $20 \mathrm{mSv}$ (averaged over any five year period, \\
& with no more than $50 \mathrm{mSv}$ in a single year) \\
Effective dose for a pregnant woman & $2 \mathrm{mSv}$ (to the surface of the abdomen during \\
& the declared term of the pregnancy) \\
Equivalent dose to the lens of the eye & $150 \mathrm{mSv}$ \\
Equivalent dose to skin, hands, and feet & $500 \mathrm{mSv}$ \\
\hline
\end{tabular}

Table 2 UK effective dose limits

\begin{tabular}{ll}
\hline Dose quantity & Annual dose limit \\
\hline Effective dose & $50 \mathrm{mSv}$ \\
$\begin{array}{l}\text { Effective dose for pregnant } \\
\text { women }\end{array}$ & $\begin{array}{c}10 \mathrm{mSv} \text { (during the declared } \\
\text { term of the pregnancy) }\end{array}$ \\
\hline
\end{tabular}

Cardiologists and other staff involved with catheterisations and interventional radiology therefore need to be monitored and may need to be designated as classified according to the IRR Guidance Notes (National Radiological Protection Board 1988) and IRR Approved Code of Practice (Health and Safety Commission 1985). It is likely that most cardiologists will not enter the classified category. This, however, can only be decided upon by regular dose monitoring.

Dose assessment requires continuous individual whole body monitoring, normally with a film or thermoluminescent dosemeter (TLD) badge worn on the trunk under the protective lead apron. There is evidence that monitoring under the apron gives a better estimate of effective dose than dosemeters worn outside the apron for the most likely combinations of scattered $x$ ray energies and lead apron thickness (Faulkner and Harrison 1988). It has been suggested that effective dose can be estimated from a single dosemeter worn outside an apron (ICRP 1982, Jones 1986) but this may overestimate the effective dose by a factor of 5-20. Further evidence is emerging that the revised ICRP tissue weighting factors, which give more weight to body organs that are protected, improved the agreement between the whole body dose estimated by monitoring beneath an apron and the effective dose.

In addition, routine or at least periodic monitoring is also required for unprotected organs, which may include eyes, hands, thyroid, or even lower legs, if their exposure is likely to contribute more than one tenth of the effective dose. This is possible if these organs receive more than one tenth of their dose limit, which is often the case in cardiology. If unprotected organs in the head are exposed to more than one tenth of their dose limit, the estimate of effective dose can be refined by calculating a weighted combination of head and body dosemeter readings (Gill et al 1980). Again film or TLD badges or TLD extremity dosemeters can be used for monitoring. When eye doses are monitored the dosemeter should be worn on the forehead or attached to the inside of normal or protected glasses. Dosemeters worn on the shoulder may overestimate eye doses (Jeans $e t$ al 1985) and are therefore not recommended. Doses to the unprotected thyroid can be monitored with an appropriate dosemeter worn over the thyroid or on the collar, while extremity doses can be measured with a TLD attached to the hand or fingertip or with a film badge worn on the wrist.

Alternatively, the dose to unprotected parts of the body can be indicated by a suitably 
calibrated electronic direct-reading, integrating dosemeter. This may be particularly useful for making initial dose assessments and to determine which body sites may require further monitoring. Audible alarm dosemeters, particularly worn outside the apron on the head or neck, may be particularly valuable for trainees and, intermittently, for more experienced operators. It is remarkable how quickly this sharpens radiation hygiene.

The duration of monitoring periods will depend on dosemeter type. For routine monitoring each film or TLD badge will normally be worn for one month but monitoring with TLD extremity dosemeters may require several days or weeks, whereas instant readout dosemeters may be used to monitor doses for individual examinations. For short monitoring periods it is important that any extrapolations to longer durations use realistic workloads.

\section{Reduction of radiation exposure}

The simplest and most effective ways to reduce irradiation of patients and staff are to employ the ALARA principle and the inverse square law. However, much can be achieved by modifying or upgrading existing equipment and paying attention to radiation shielding. In all hospitals there are radiologists who provide a body of experience that may be of value to cardiologists. Full cooperation between cardiologists and radiologists will help to reduce the exposure to radiation.

\section{PHYSICAL BARRIERS}

The patient's thorax becomes a powerful source of scattered $x$ rays. The scattered radiation is particularly intense at table height on the tube side of the table and in certain projections (LAO craniocaudal and lateral). This scatter can be interrupted by physical barriers commonly made from lead-impregnated rubber or leaded glass. A simple, ceiling mounted, cantilever-suspended, leaded glass screen, which incorporates a leaded skirt, can reduce secondary scatter to the torso and head of the operator by up to a factor of 10 . Such screens are readily available from all major manufacturers of cineangiographic equipment. It is also possible to mount leaded rubber skirts on the table side or in the form of a saddle across the patient's thighs. These will give additional substantial reductions in scattered radiation to the operator. They can usually be constructed in-house from old lead aprons.

\section{PERSONAL PROTECTION}

Many makes and types of lead apron are available. These come in various lead equivalent thickness from $0.25 \mathrm{~mm}$ to $0.5 \mathrm{~mm}$. It is advisable to wear the heaviest apron that can be used with comfort. Many of the new makes of apron give much better thyroid and lateral thoracic protection (especially important to female staff) than the obsolete British Standard BS3793 aprons. The older type of apron can be upgraded by Velcro belts to keep the side apertures closed and separate thyroid collars can be added. This latter precaution is frequently overlooked and it is important because the thyroid is very radiosensitive. So too is the lens of the eye. Leaded glass prescription spectacles are available but they are heavy and can become uncomfortable during a long intervention. If a leaded glass cantilever screen is available and properly used, leaded spectacles are not necessary.

\section{FLUOROSCOPY}

Fluoroscopy was originally used mainly for beam positioning of the cine run. However, with the advent of interventional procedures such as angioplasty, ductus and septal defect closures, and, in particular, radiofrequency ablation of accessory atrioventricular pathways, fluoroscopy times can be exceptionally long. It is therefore vital to use low dose rate fluoroscopy. A modern sensitive image intensifier must be used and two variations on standard continuous fluoroscopy are available-pulsed fluoroscopy and digital noise integration

Pulsed fluoroscopy can reduce radiation exposures by up to $30 \%$ and its short $x$ ray pulses prevent motion blurring of fast moving details. It is therefore useful when very accurate positioning of balloons, guidewires, or interventional devices is required. It has the disadvantage that if the pulse rate is too low a "Charlie Chaplin" or "slide show" effect is obtained. Because there is a trade off between dose rate and the number of pulsed fluoroscopic frames per second most centres still use standard continuous fluoroscopy.

Digital noise integration with a real time motion detector in the digital processor and the addition of real time edge enhancement, can halve the fluoroscopic dose in digital systems.

\section{CINEANGIOGRAPHY}

Of all radiodiagnostic procedures, cineangiography delivers one of the highest radiation dosages to patients, and consequently to staff. This is because high resolution images at high frame rates in multiple projections are needed. The sensitivity of image intensifiers has been greatly improved but it may also be desirable to reduce the frame rate and the dosage per frame.

\section{Frame rate reduction}

The human eye registers flicker at frame rates of less than 20 frames per second (fps). Most conventional cineangiographic systems run at 25 or $30 \mathrm{fps}$, but some older laboratories still operate at $50 \mathrm{fps}$. Each laboratory should use the lowest acceptable frame rate.

\section{Dose reduction per frame}

Because of the physical principles involved in producing $x$ ray images there is a compromise between decreasing the dose and increasing the amount of "noise". There is therefore a level below which quantum mottle degrades images to unacceptable levels.

\section{DIGITAL CARDIAC ANGIOGRAPHY}

The physical constraints of conventional 
cineangiography leave little room for development. However, digital imaging technology can be used in cardiac angiography. Like cineagiography, reducing the dose increases the quantum mottle. But digital contrast enhancement can produce images of satisfactory contrast and resolution with up to $30 \%$ less radiation per frame than cineangiography. With a technique known as "infilling" frame rates as low as 12.5 fps can be run without appreciable flicker thus reducing to a quarter the dose to patient and staff at $50 \mathrm{fps}$.

\section{Digital review facility}

In long or complicated interventional procedures the operator may need to see a repeated image to check the position of a catheter or guidewire. Digital equipment has a continuous replay mode, which allows the operator to reflect on the progress of the case, rather than giving multiple repeat bursts of fluoroscopy. This may seem to be only a subjective advantage but in practice it is a real one. A similar advantage is given by a "digital road mapping" facility.

\section{Operator risk}

The hands and eyes are at particular risk of significant radiation exposure even when an operator follows the correct guidelines for radiation protection. The doses incurred by the eyes and hands during the various procedures performed in the catheterisation laboratory depend on the apparatus, the nature of the procedures performed, and the skill of the operators. Most references to physician dosage incurred during cardiac catheterisation are unhelpful because they date back to the period when intensifiers were inefficient, apparatus was of the fixed tube variety, and catheterisation skills were poorly developed. Current practice uses sensitive image amplifiers, compound angulated $x$ ray sets, and much shorter examination times because of the greater skills of the operators.

Begg et al (1975) using the Philips Cardiodiagnost and Sones technique required a mean fluoroscopy time of 8.4 minutes with an average cine recording time at $30 \mathrm{fps}$ of 54 seconds. The index finger dose was $0.28 \mathrm{mSv}$ and the lens dose was $0.009 \mathrm{mSv}$ per procedure with the lead curtain in position and doses were 10 to 20 times higher if the lead curtain was not in position. Begg et al commented that the dose delivered by cine radiography was almost 10 times greater than that needed for fluoroscopy and that use of the lead overleaf curtain reduced radiation by factors as great as 18:1. They also commented that the radiation dose to the angiographer was 5-10 times greater in intensity in the LAO projection than in the RAO projection.

Balter et al (1978) compared the Sones technique of coronary angiography with and without the protective lead curtain at the Cleveland clinic with measurements at $\mathrm{St}$ Joseph's Hospital with the lead curtain. The lead curtain reduced dose to the eye from $0.06 \mathrm{mSv}$ per procedure to $0.019 \mathrm{mSv}$ per procedure, and with shorter fluoroscopy and cine times at St Joseph's Hospital the eye dose was only $0.004 \mathrm{mSv}$ per procedure. Similarly, the hand dose was reduced from $0.08 \mathrm{mSv}$ per procedure without the lead curtain to $0.021 \mathrm{mSv}$ per procedure with the lead curtain. It was $0.003 \mathrm{mSv}$ per procedure at St Joseph's Hospital.

Finci et al (1987) compared the radiation exposure to the operator from straightforward coronary angiography with that from single and double vessel coronary angioplasty. Their paper does not make it clear whether their apparatus was of the most modern variety because they obtained longitudinal tilt by rotating the table, rather than by rotating the tube. They also used biplane ventriculography. For angiography the fluoroscopy time was 223 seconds, for single vessel angioplasty it was 1023 seconds, and for double vessel angioplasty it was 1186 seconds. For angiography the cine time was 49 seconds, for single vessel angioplasty it was 32 seconds, and for double vessel angioplasty it was 49 seconds. Finci et al calculated that for angiography the dose to the operator was $0.06 \mathrm{mSv}$ for the eyes and $0.3 \mathrm{mSv}$ for the left hand. For single vessel angioplasty the dose to the eyes was $0.04 \mathrm{mSv}$ and to the left hand it was $0.3 \mathrm{mSv}$, and for double vessel angioplasty the eye dose was $0.03 \mathrm{mSv}$ and the dose to the left hand was $0.47 \mathrm{mSv}$. Although their fluoroscopy times for angiography were quite short the eye dose is significantly higher than that obtained by the previous workers. This may reflect the use of biplane filming and relatively unsophisticated apparatus.

Calkins et al (1991) measured the radiation dosages incurred by the operator during intracardiac catheter ablation procedures. Even with protective lead glass in position they found the dose to the left hand was 1 $\mathrm{mSv}$ per procedure and the dose to the left maxilla, the equivalent of the eye dose, was $0.28 \mathrm{mSv}$ per procedure.

From these figures (table 3 ) it is possible to estimate the number of cases of each procedure that the trained operator can perform in the course of a year and still remain within three tenths of the relevant dose limit (45 $\mathrm{mSv}$ per year for the eyes and $150 \mathrm{mSv}$ per year for the hands) (table 4). In table 4 it is assumed that each operator performs only one type of procedure.

Because most cardiologists undertake various procedures the factors in table 5 must be used to calculate the approximate totals for a mix of procedures. The total number of cases allowable in a year for any individual operator is also heavily influenced by that individual's radiation hygiene and by the equipment that is used. On current best estimates, with modern apparatus, the eye dose incurred during coronary angiography from the arm ranges from about $0.004 \mathrm{mSv}$ to $0.02 \mathrm{mSv}$ when a protective lead curtain but not a lead glass eye shield is used. The worst case would allow an operator to perform over 2000 coronary angiograms without eye irradiation leading to their becoming a classified operator. 
Table 3 Average radiation doses Upper limit of dose/procedure ( $\mathrm{mSv}$ )

\begin{tabular}{lcc}
\hline Procedure & Eye & Hand \\
\hline Simple angiography & 0.02 & 0.02 \\
Angioplasty & 0.03 & 0.3 \\
Pacemakers & 0.05 & 0.15 \\
Catheter ablations & 0.3 & 1.0 \\
3/10 Dose limit & 45 & 150 \\
\hline
\end{tabular}

Table 4 Approximate annual number of individual procedures to achieve three tenths of dose limits (if no other procedures are undertaken

\begin{tabular}{lrr}
\hline Procedure & Eye & Hand \\
\hline Angiography & 2250 & 7500 \\
Angioplasty & 1500 & 500 \\
Pacemaker & 900 & 1000 \\
Catheter ablations & 150 & 150 \\
\hline
\end{tabular}

Hand doses range from $0.02 \mathrm{mSv}$ down to $0.003 \mathrm{mSv}$ per case, allowing an individual to study more than 7000 cases a year before classification on the basis of hand irradiation.

For angioplasty the figures are somewhat inconsistent but they suggest that while the eye doses are little different from those of simple coronary angiography the hand doses are about ten to one hundred times higher. If the figures of Finci et al (1987) are correct operators would be limited by hand doses to 500 procedures per year. For catheter ablations the information seems well based. The eye dose, even with a protective lead glass, is around $0.3 \mathrm{mSv}$, giving a limit of 150 cases a year. The hand dose is virtually $1 \mathrm{mSv}$ per case, giving a similar limit of about 150 cases a year. Clearly the operator dose in catheter ablations may easily lead to classification. No direct measurements are available for operator dose during pacemaker insertions but Jeans et al (1985) estimated an eye dose of $0.05 \mathrm{mGy}$ and a hand dose of $0.15 \mathrm{mGy}$ per procedure, figures that are difficult to reconcile with those given for angiography.

Such calculations clearly do not apply to trainees (Renaud 1992), who take significantly longer than their senior colleagues and incur a higher radiation dose. The radiation burden of trainees should be very closely supervised and remain within the limits. Trainees should do fewer procedures until they gain sufficient expertise.

\section{Investigational and interventional procedures}

PAEDIATRIC INTERVENTION

Paediatric cardiological facilities are available at 17 centres in the United Kingdom. There

Table 5 Maximum workload based on exposure to radiation (factor $x$ number of Procedures)

\begin{tabular}{llllll}
\hline Exposure & $\begin{array}{l}\text { Simple } \\
\text { Angiogram }\end{array}$ & Angioplasty & Pacemaker & $\begin{array}{l}\text { Catheter } \\
\text { ablation }\end{array}$ & $\begin{array}{l}\text { Total } \\
\text { permitted } \\
\text { score }\end{array}$ \\
\hline Eye & 0.02 & +0.03 & +0.05 & +0.3 & $<45$ \\
Hand & 0.02 & +0.3 & +0.15 & +1.0 & $<150$ \\
Eye and Hand & 0.02 & +0.09 & +0.05 & +0.3 & $<45$ \\
\hline
\end{tabular}

are between two and six consultant paediatric cardiologists. Thus about 55 consultants and 20 junior staff in the United Kingdom are involved in the catheter laboratory work.

Each year about 4000 paediatric cardiac catheterisation procedures are performed in these centres. Most are diagnostic procedures but about $33 \%$ are interventional (from $10 \%$ to $60 \%$ for different centres). There has been an annual increase in the number of interventions since 1982: before that date all procedures were diagnostic. Diagnostic catheterisation lasts from 30 minutes to two hours whereas interventional procedures take from two to four hours. The types of interventions have also changed over the last 10 years. Initially only balloon dilatation of the pulmonary valve was accepted as an alternative to surgery, but nowadays many other congenital cardiac lesions are also amenable to non-surgical treatment. These include balloon dilatation in aortic stenosis, coarctation, and re-coarctation; in branch pulmonary artery stenosis; in tetralogy of Fallot, and in stenosed venous channels. Coil embolisation for arteriovenous fistulas, umbrella occlusion of arterial ducts and laser valvotomy for congenitally atretic valves are becoming acceptable and recognised treatments. More and more stents are being implanted and nonsurgical closure of atrial and some ventricular septal defects may become routine in the next two years.

In the early part of the experience of every paediatric cardiologist interventional procedures take a long time to complete and involve long fluoroscopy times. With experience these times become shorter. Some of the treatments are for congenital lesions with high risks from surgery and so the risks of radiation have to be balanced against the risks of the lesion and its alternative treatments. However, every attempt is made to ensure that the patient receives the lowest dose possible.

\section{ADULT CORONARY INTERVENTIONS \\ Coronary angiography}

The definition of the coronary anatomy by invasive techniques forms the larger part of the workload of any catheter laboratory. In 1990 a total of 58197 coronary angiographic procedures were undertaken in the United Kingdom by 46 of the 51 cardiac units with coronary angiography facilities. Each unit performed between 274 and 3300 procedures. Approximately $25 \%$ of these patients went on to coronary artery bypass grafting (CABG) and another $14.5 \%$ had percutaneous transluminal coronary angioplasty (PTCA).

\section{Coronary angioplasty}

The past 12 years have seen the emergence of PTCA for the treatment of some forms of coronary narrowing. Each cardiologist has had to perform many more procedures, with a concomitant increase in the risk of radiation exposure. More recently the scope for intervention has increased. As the experience of 
operators has grown, along with enhancements in technology, so has the ability to treat more complex coronary disease.

A survey in 1990 by the British Cardiovascular Intervention Society (BCIS) showed that the number of angioplasties in the United Kingdom was 7445 performed at 51 centres, with individual centres doing between 10 and 428 procedures. Data on PTCA were received from another five centres for which information about cardiac catheterisations was not available. The total number of PTCAs performed in the United Kingdom in 1990 was 8459.

The exposure to radiation is related to the experience of the operator, the complexity of the procedure, the nature of any additional intervention carried out, and factors related to equipment and procedure. In the United Kingdom the experience of coronary angioplasty is small with over $50 \%$ of centres (27) performing fewer than 150 procedures per annum. Sixteen centres do fewer than 100 procedures and five do fewer than 50, whereas in the United States more than $66 \%$ of procedures are carried out by $30 \%$ of the catheter laboratories. Worldwide figures indicate that the coronary angioplasty procedure rate will grow at about $12 \%$ per annum and this level of growth has been seen in previous years in the United Kingdom.

Additional interventional procedures are now being seen in the United Kingdom and various drills, slicing devices, lasers, and stents are being used in a few cases. In 1990, 135 such procedures were undertaken. These are usually longer, more complex procedures with increased radiation exposure time.

Currently, 180 cardiologists perform coronary angioplasty procedures. BCIS has indicated that about 400 PTCAs per million are required. The present workload is about 170 per million. Each operator performs just under 50 procedures per annum. To reach the BCIS target each operator will have to more than double his or her workload.

\section{RADIOFREQUENCY ABLATION}

Few centres within the United Kingdom offer radiofrequency ablation. At these centres one or two consultants perform the procedures and this is likely to remain the pattern for some time. As well as the operator up to two nurses, two technicians, and two radiographers will be exposed to radiation during the procedures. Nursing and radiography staff are routinely monitored and in most studies receive substantially less radiation than the primary operator.

A radiofrequency database has been set up by the British Pacing and Electrophysiology Group (BPEG). Currently from 50 to 110 ablations per year are performed by radioablation at the six main centres.

The clinical indications for radiofrequency ablation include "atrioventricular nodal" pathways, accessory pathways, and ectopic arrhythmogenic sites within the atrium and ventricle. Because of the variety of conditions treated the time taken per case ranges from one to six hours with screening times of between 12 minutes and 85 minutes. A total of 480 cases were identified from the six centres and the average $x$ ray screening time was 62 minutes (figure).

The individual operator will therefore be exposed to between 2100 and 4600 minutes per year of extra radiation. We expect that the number of cases will double within the next two years. This increase could double individual radiation exposure unless more specialists are trained in this technique.

Though there is a learning curve radiation exposure times for radiofrequency ablation are unlikely to become appreciably shorter because the figures quoted above are similar to those of large centres in the United States and Europe.

\section{PACEMAKERS}

Each year in the United Kingdom about 13000 pacemakers are implanted by at least 200 cardiologists in more than 125 pacemaker centres. The implantation rate is less
Recent trends in the reduction of procedure and screening times (in minutes) for radiofrequency ablation in the United Kingdom. Data kindly provided by David Cunningham on behalf of the British Pacing and Electrophysiology Group.

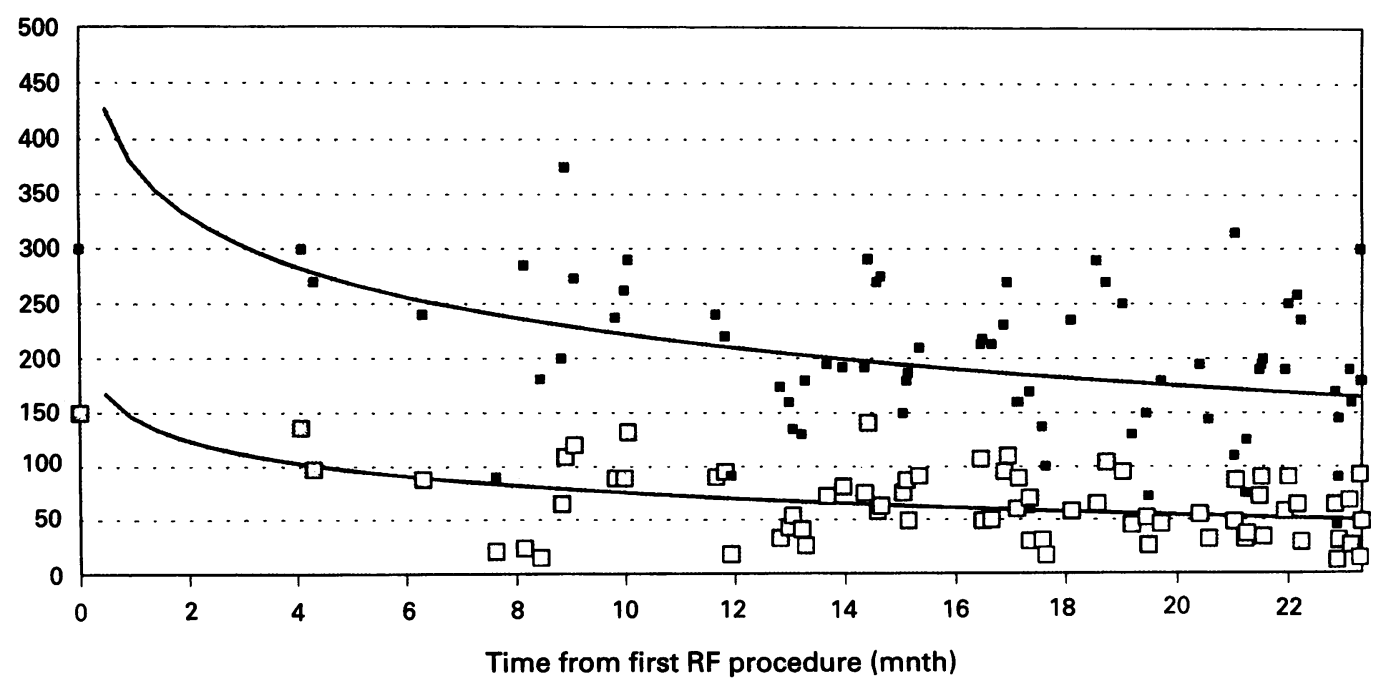

Time from first RF procedure (mnth) 
than in most other European and North American countries. The workload per centre ranges from 25 to 700 pacemakers per year and individual cardiologists may implant up to 200 pacemakers each year. About $80 \%$ of all implants are single chamber pacemakers. Pacemaker implantation takes 2-10 minutes of fluoroscopy time with an experienced operator. However, much of the pacemaker implantation workload is undertaken by junior staff who may take much longer.

In recent years there has been an appropriate trend towards the implantation of more dual chamber units but an inappropriate trend towards the implantation of pacemakers by less experienced operators at district general hospitals. These factors have generally resulted in a greater total radiation exposure but because more cardiologists are now implanting pacemakers the effect on the exposure of individuals to radiation is more difficult to ascertain. Cardiologists now implant endocardial defibrillators. This procedure probably involves a substantially higher radiation burden than does dual chamber pacing and although the total number of implantations in the United Kingdom is low the workload is presently concentrated in a few centres.

\section{OTHER ADULT CARDIAC INTERVENTIONS}

Some forms of stenosed heart valves can be treated by balloon dilatation and some channels can be closed by deployable balloons or baffles (for example, the patient ductus arteriosis occluder). Techniques are being developed and the number of procedures, the indications, and long-term results are unclear. Development will continue and allowance must be made for this when the potential radiation exposure of the cardiologist is assessed. Balloon dilatation of valves probably involves a similar radiation burden as angioplasty.

In 1990 dilatation of the mitral valve was the most common valve procedure in adults in the United Kingdom with 20 centres performing 213 procedures. The total number of all types of valve dilatations was 309 .

\section{Voluntary registration scheme}

At present it seems likely that, with the possible exception of cardiologists undertaking catheter ablation procedures, the average potential exposure to radiation is not excessive. However, workloads, work practices, and equipment standards vary considerably. Furthermore, in most areas the number of investigations and interventional procedures which involve exposure to radiation are set to increase. There are no plans to increase commensurately the number of cardiologists and/or radiologists who undertake these procedures. Thus the exposure of cardiologists to radiation should be monitored more carefully in the future than in the past. Some form of prospective audit should be carried out:

(a) The most strict form of audit is compulsory registration of operators. This would be difficult to enforce and would be counterproductive because it would alienate many operators.

(b) At present a basic level of radiation monitoring for all staff is achieved with dosemeter badges. This aims to satisfy legislative requirements but is inadequate for a dose audit because the workload (number and type of procedures) and doses to unprotected organs or extremities may not be recorded. Standard dosimetry should be instituted. Two badges should be worn-one under the lead apron on the hip nearest the $x$ ray tube and the other at the neck level on the thyroid collar on the outside of the apron.

(c) A voluntary registration scheme is attractive because a body of reasonably detailed information could be obtained from at least a proportion of operators and because, as interest and awareness in this subject grows, the number of people participating in the scheme will increase. A voluntary system has the benefit that those participating in it would be sufficiently interested to complete some form of annual return.

A voluntary registration scheme with data returned annually is the most useful form of audit for assessment of the exposure of cardiologists to radiation. All interventional cardiologists and others frequently exposed to radiation should be encouraged to register.

\section{INFORMATION REQUIRED}

It is considered that registration of individuals, rather than of catheterisation laboratories is appropriate, because each cardiologist may work in an individual way and in more than one laboratory and the dose to an individual is of most concern. There is no reason why several or all individuals from one centre should not be registered.

The annual return from each individual should contain the following information:

- Name and institutions where the procedures were carried out.

- The number of each type of diagnostic and interventional procedures carried out by that individual during the year. All forms of procedure that require ionising radiation should be logged, including diagnostic cardiac angiography, coronary angioplasty, valve dilatation and other interventional techniques, paediatric cardiac catheterisation, electrophysiology, pacemaker implantation, and ablation procedures. The log should include the length of screening time, the equipment used and whether the individual was first or second operator.

- Results of the monitoring procedures undertaken by the registrant as a consequence of participating in this scheme.

\section{ORGANISATION OF REGISTRATION SCHEME}

It is clear that this scheme will require a database to be maintained with facilities for mail out and some facilities for analysis. The two most suitable organisations that might run the database are the British Cardiac Society and the Cardiac Radiology Group of the 
Royal College of Radiologists. It is appropriate for the British Cardiac Society to run the database in conjunction with the radiologists in order to maintain proper input and interest from both groups.

The database should be open to participation by all those involved in invasive techniques whether junior medical staff or consultant and whether radiologist or cardiologist.

The database should be endorsed by the British Cardiac Society and its affiliated groups such as BPEG, BPCS and BCIS. Their members should be expected to join this scheme. Cardiologists in training should log radiation exposure in their training manuals and submit annual reports to the database.

\section{Summary and recommendations}

The development of interventional techniques that require substantial fluoroscopy and cinangiography times has increased the exposure to radiation of interventional cardiologists. At the same time the maximum permitted exposure to radiation has been significantly reduced. It is therefore appropriate to alert all cardiologists using ionising radiation to the need for radiation hygiene. The recommendations set out below are designed to promote this heightened awareness. 1 Cardiologist exposure to radiation should be monitored with two dosemeter badges, one placed beneath the lead apron and one outside the apron.

2 The radiation dose reports should be returned to the cardiologist and to the catheter laboratory(ies). The information should be charted in the area of the catheter laboratory(ies).

3 The British Cardiac Society and/or its affiliated groups should be responsible for organising specific cardiology radiation courses.

4 Cardiologists should be encouraged to join a voluntary register to log their exposure to radiation. The register should be set up and maintained by the British Cardiac Society.

5 Recording of exposure to radiation should be part of the training log of cardiologists in training.

6 The workload of cardiologists should be set at a level less than would be likely to exceed three tenths of all relevant dose limits of radiation exposure.

7 Where necessary staffing levels should be increased or practice patterns reviewed in order to prevent excessive radiation doses to cardiologists.

8 When a cardiac catheterisation laboratory is replaced or upgraded careful consideration should be given to radiation protection of staff and the use of low dose equipment.

\section{Bibliography}

Agarwal SK, Friesen EJ, Huddleston AL, Rao RP. The effectiveness of glass lenses in reducing exposure to the eyes. Radiology 1978;129:810-11.

Balter S, Sones FM Jr, Brancato R. Radiation exposure to the operator performing cardiac angiography with U-arm systems. Circulation 1978;58:925-65.

Begg FR, Hans LR. Radiation exposure to angiographer during coronary arteriography using the $U$ arm image amplifer. Cath Cardiovasc Diag 1975;1:261-5.

Cagnon CH, Benedict SH, Mankovich NJ, Bushberg JT Seibert JA, Whiting JS. Exposure rates in high-level-control fluoroscopy for image enhancement. Radiology 1991;178: 643-6.

Calkins H, Niklason L, Sousa J, El-Atassi R, Langberg J, Morady F. Radiation exposure during radiofrequency catheter ablation of accessory atrioventricular connections. Circulation 1991;84:2376-82.

Cousin AJ, Lawdahl RB, Chakraborty DP, Koehler RE. The case for radioprotective eyewear/facewear. Practical implications and suggestions. Invest Radiol 1987;22:688-92.

Dash $H$, Leaman DM, Operator radiation exposure during percosuring Cardiol 1984;4:725-8.

Faulkner K, Harrison RM. Estimation of effective dose equivalent to staff in diagnostic radiology. Phys Med Biol 1988; alent to staff

Finci I Meier B, Steffenino G, Roy $P$, Rutishauser W. Radiation exposure during diagnostic catheterisation and single and double vessel percutaneous transluminal coronary angioplasty. $A m \mathcal{F}$ Cardiol $1987 ; 60: 1401-3$.

Gertz EW, Wisneski JA, Gould RG, Akin JR. Improved radiation protection for physicians performing cardiac catheterisation. Am $¥$ Cardiol 1982;50:1283-6.

Gill JR, Beaver PF, Dennis JA. The practical implications of ICRP recommendations regarding dose equivalent limits for workers to staff in diagnostic $x$-ray departments. Proceedings of fifth international Congress of the IRPA Jerusalem: IRPA, 1980:15-18.

Grant SCD, Bennet DH, Mather JM. Reduction of radiation exposure to the cardiologist during coronary angiography exposure to the cardiologist during coronary angiography
by the use of a remotely controlled mechanical pump for by the use of a remotely controlled mechanical pump for
injection of contrast medium. Cath Cardiovasc Diag 1992; 25:107-9.

Health and Safety Commission. The protection of persons against ionising radiations arising from any work activity. Approved Code of Practice. London: HMSO 1985.

Health and Safety Commission. Dose limitation-restriction of exposure. Approved Code of Practice, Part 4. London: HMSO, 1991 .

Holmes DR Jr, Wondrow MA, Gray JE, Vetter RJ, Fellows JL, Julsrud PR. Effect of pulsed progressive fluoroscopy on reduction of radiation dose in the cardiac catheterisation reduction of radiation dose in the cardiac cath

ICRP. Recommendations of the International Commission on Radiological Protection. Ann ICRP 1977:publication 26.

Radiological Protection. Ann ICRP 1977:publication 26.
ICRP. General principles of monitoring for radiation protecICRP. General principles of monitoring for radia
tion of workers. Ann ICRP 1982:publication 35.

tion of workers. Ann ICRP 1982:publication 35 .
ICRP. 1990 Recommendations of the International Commission on Radiological Protection. Ann ICRP 1990 publication 60

The ionising radiations regulations 1985 . Statutory Instrument No 1333. London: HMSO, 1985.

Jeans SP, Faulkner K, Love HG, Bardsley RA. An investigation of the radiation dose to staff during cardiac radiological studies. Br 7 Radiol 1985;58:419-28.

Jeans SP, Faulkner K, Love HG, Bardsley RA. Routine monitoring of eye dose (reply). Br f Radiol 1985;58:1227-8.

Kosnik LT. Personnel exposure in the cardiac catheterisation laboratory. Health Phys 1986;50:144-7.

Klein LS. Radiofrequency catheter ablation. Safety and practicality. Circulation 1991;84:2594-7.

McParland BJ, Nosil J, Burry B. A survey of the radiation exposures received by the staff at two cardiac catheterisation laboratories. Br $\mathcal{F}$ Radiol 1990;63:885-8.

National Radiological Protection Board. Guidance notes for the protection of persons against ionising radiations arising from medical and dental use. London: HMSO, 1988

National Radiological Protection Board. Board advice following publication of the 1990 recommendations of the ICRP NRPB-M321. Chilton: NRPB, 1991.

Renaud L. A 5 year follow up of the radiation exposure to inroom personnel during cardiac catheterisation laboratory. ₹ Am Coll Cardiol 1990;15:159-62.

Russel JGB. The radiogenic hazards of working in a radiolog department. Clin Radiol 1991;44:145-6. 